\title{
Newly discovered cichlid fish biodiversity threatened by hybridization with non-native species
}

\author{
Tabitha Blackwell ${ }^{1 *}$, Antonia G.P. Ford ${ }^{2 *}$, Adam G. Ciezarek ${ }^{3 *}$, Stephanie J. Bradbeer ${ }^{1}$, \\ Carlos A. Gracida Juarez ${ }^{1}$, Benjamin P. Ngatunga ${ }^{4}$, Asilatu H. Shechonge ${ }^{4}$, \\ Rashid Tamatamah ${ }^{4}$, Graham Etherington ${ }^{3}$, Wilfried Haerty ${ }^{3}$, Federica Di Palma ${ }^{3,5}$, \\ George F. Turner ${ }^{6}$ and Martin J. Genner ${ }^{1}$
}

${ }^{1}$ School of Biological Sciences, University of Bristol, Life Sciences Building, 24 Tyndall Avenue, Bristol, BS81TQ, United Kingdom

${ }^{2}$ Department of Life Sciences, Whitelands College, Holybourne Avenue, University of Roehampton, London, SW154JD, United Kingdom

${ }^{3}$ Earlham Institute, Norwich Research Park Innovation Centre, Colney Ln, Norwich, NR47UZ, United Kingdom

${ }^{4}$ Tanzania Fisheries Research Institute (TAFIRI) P.O. Box 9750. Dar es Salaam. Tanzania.

${ }^{5}$ Department of Biological and Medical Sciences, University of East Anglia, Norwich, NR47TJ, UK

${ }^{6}$ School of Biological Sciences, Bangor University, Bangor, Gwynedd, LL57 2UW, United Kingdom

*Authors contributed equally

Correspondence: Martin J. Genner, School of Biological Sciences, University of Bristol, Life Sciences Building, 24 Tyndall Avenue, Bristol, BS8 1TQ, United Kingdom. Email m.genner@bristol.ac.uk

\begin{abstract}
Invasive freshwater fish systems are known to readily hybridize with indigenous congeneric species, driving loss of unique and irreplaceable genetic resources. Here we reveal that newly discovered (20132016) evolutionarily significant populations of Korogwe tilapia (Oreochromis korogwe) from southern Tanzania are threatened by hybridization with the larger invasive Nile tilapia (Oreochromis niloticus). We use a combination of morphology, microsatellite allele frequencies and whole genome sequences to show that $O$. korogwe from southern lakes (Nambawala, Rutamba and Mitupa) are distinct from geographically-disjunct populations in northern Tanzania (Zigi River and Mlingano Dam). We also provide genetic evidence of $O$. korogwe x niloticus hybrids in three lakes and demonstrate heterogeneity in the extent of admixture across the genome. Finally, using the least admixed genomic regions we estimate that the northern and southern $O$. korogwe populations most plausibly diverged approximately 140,000 years ago, suggesting that the geographical separation of the northern and southern groups is not a result of a recent translocation, and instead these populations represent independent evolutionarily significant units. We conclude that these newly-discovered and phenotypically unique cichlid populations are already threatened by hybridization with an invasive species, and propose that these irreplaceable genetic resources would benefit from conservation interventions.
\end{abstract}

Keywords: Introgression, admixture, biodiversity conservation, cichlid fishes, population genomics, geometric morphometrics. 
Freshwater ecosystems are undergoing rapid changes in biodiversity due to the interacting effects of habitat degradation, over-exploitation, water pollution, flow modification and species invasion (Sala $e t$ al. 2000; Dudgeon et al. 2006; Millennium Ecosystem Assessment, 2016). As human population sizes continue to rise, and climate change becomes an ever-increasing threat, these impacts are predicted to grow (Martinuzzi et al. 2014; Arroita et al. 2017; Kalacska et al. 2017). A specific issue is hybridization between introduced species and native fish species. This has been reported in closely-related species from multiple fish families, including the salmonids (Muhlfield et al. 2014; Mandeville et al. 2019), cichlids (Firmat et al. 2013; Shechonge et al. 2018) and cyprinids (Almodóvar et al. 2012; Hata et al. 2019), and is likely to become increasingly common due to the spread of freshwater species for aquaculture and inland fisheries enhancement (Deines et al. 2014). However, the full evolutionary and ecological consequences of hybridization between invasive and native species are typically unclear, and further studies of the impact of hybridization events on native biodiversity are required.

African inland fisheries depend heavily on "Tilapias" (Brummett \& Williams, 2000), a group of cichlids that includes the commercially important genera Oreochromis, Sarotherodon and Coptodon. Among the most favoured of these species is the Nile tilapia, Oreochromis niloticus, which has broad physiological tolerances of environmental conditions, potential for rapid growth, and thus has been widely translocated across the continent (Josupeit, 2010; Dienes et al. 2014). However, because of these traits the species is also highly invasive within its introduced range (Ogutu-Ohwayo, 1990; Canonico et al. 2005; Deines et al. 2017). Moreover, O. niloticus is also known to hybridize with native Oreochromis species at the locations where it has been introduced, for example with Oreochromis mossambicus in Southern Africa (D'Amato, 2007), Oreochromis esculentus in Lake Victoria (Angienda et al. 2011) and Oreochromis urolepis and Oreochromis jipe in Tanzania (Shechonge et al. 2018; Bradbeer et al. 2019). However, despite the growing concern surrounding the impacts of hybridization on native Oreochromis populations, the potential loss of unique native genetic diversity due to hybridization with $O$. niloticus remains poorly studied. This is an important area to study because shifts in cichlid fish biodiversity and community composition can lead to fundamental changes in ecosystem functioning (Lévêque 1995), and loss of potential valuable genomic resources for future Oreochromis aquaculture strain development (Eknath \& Hulata 2009; Lind et al. 2012).

Tanzania has a rich diversity of Oreochromis species, and preservation of this natural species and its genetic diversity has been recognized as an important conservation goal, given threats of changing environment and hybridization with invasive Oreochromis species (Shechonge et al. 2018). Recently (between 2013 and 2016) populations of Oreochromis korogwe were discovered in three lakes in southern Tanzania near Lindi (Lakes Rutamba, Nambawala and Mitupa; hereafter referred to as 'southern populations'; Fig. 1). Previously this species was only known from the Pangani and Zigi river catchments in northern Tanzania (hereafter referred to as 'northern populations'; Fig. 1), some $500 \mathrm{~km}$ north of Lindi (Trewavas, 1983; Bradbeer et al. 2018; Shechonge et al. 2019); the holotype is a specimen from Korogwe in the Pangani catchment (Lowe, 1955). The close evolutionary relationship between representatives of the northern and southern populations has been confirmed in a recent genus-level phylogeny, based on $\sim 3000$ bp of nuclear DNA across six loci and $\sim 1500 \mathrm{bp}$ of mtDNA (Ford et al. 2019, where they were referred to as $O$. korogwe and $O$. sp. Rutamba, respectively). Importantly, the rivers between Lindi and the Pangani are populated naturally only by $O$. urolepis. Such a large geographic discontinuity in the apparent natural distribution of Oreochromis is not known in any other species (Trewavas 1983, Shechonge et al. 2019), and is rare in other African freshwater fishes (e.g. Skelton 2001). Importantly, in all three of the southern lakes studied, the invasive O. niloticus was also found, and the presence of phenotypically intermediate individuals suggested the presence of hybrids.

In this study we aimed to characterize the diversity and origins of the newly discovered southern populations of $O$. korogwe. We first quantified the extent of hybridization between these populations and invasive Nile tilapia. We then evaluated the possibility that the southern population could be a newly recognized evolutionarily significant unit (sensu Fraser \& Bernatchez 2001), by comparing genetic and morphological differences with northern $O$. korogwe. We also investigate varying levels of admixture across the genome from $O$. niloticus into southern $O$. korogwe. These results demonstrate that an evolutionarily significant unit is threatened by hybridization with an invasive species, and add to a 
bioRxiv preprint doi: https://doi.org/10.1101/2020.08.06.240002; this version posted August 7, 2020. The copyright holder for this preprint (which was not certified by peer review) is the author/funder, who has granted bioRxiv a license to display the preprint in perpetuity. It is made available under aCC-BY 4.0 International license.

growing body of evidence for the heterogenous nature of admixture across genomes during hybridization events.

\section{Materials and Methods}

Study sites and sample collection.

Oreochromis korogwe, O. niloticus and their potential hybrids were collected from southern Tanzania (Lake Rutamba, Lake Nambawala, and Lake Mitupa) on the 14 August 2013, 2-4 May 2015 and 21-27 October 2016 (Fig. 1; Table 1). Samples of O. korogwe were collected from northern Tanzania (Zigi River and Mlingano Dam) on the 18 August 2015 (Fig. 1; Table 1). Samples were collected either using multi-mesh gill nets, a seine net, or from purchasing from local fishermen. Multi-mesh nets measured $30 \mathrm{~m}$ in length with a stretched depth of $1.5 \mathrm{~m}$ height, and 12 panels each 2.5 meters long. Mesh sizes for panels were in the following order $43 \mathrm{~mm}, 19.5 \mathrm{~mm}, 6.25 \mathrm{~mm}, 10 \mathrm{~mm}, 55 \mathrm{~mm}$, Need $8 \mathrm{~mm}, 12.5 \mathrm{~mm}$, $24 \mathrm{~mm}, 15.5 \mathrm{~mm}, 5 \mathrm{~mm}, 35 \mathrm{~mm}$ and $29 \mathrm{~mm}$. The seine net measured $30 \mathrm{~m}$ in length, $1.5 \mathrm{~m}$ in height with $25.4 \mathrm{~mm}$ mesh and fine mesh cod end.

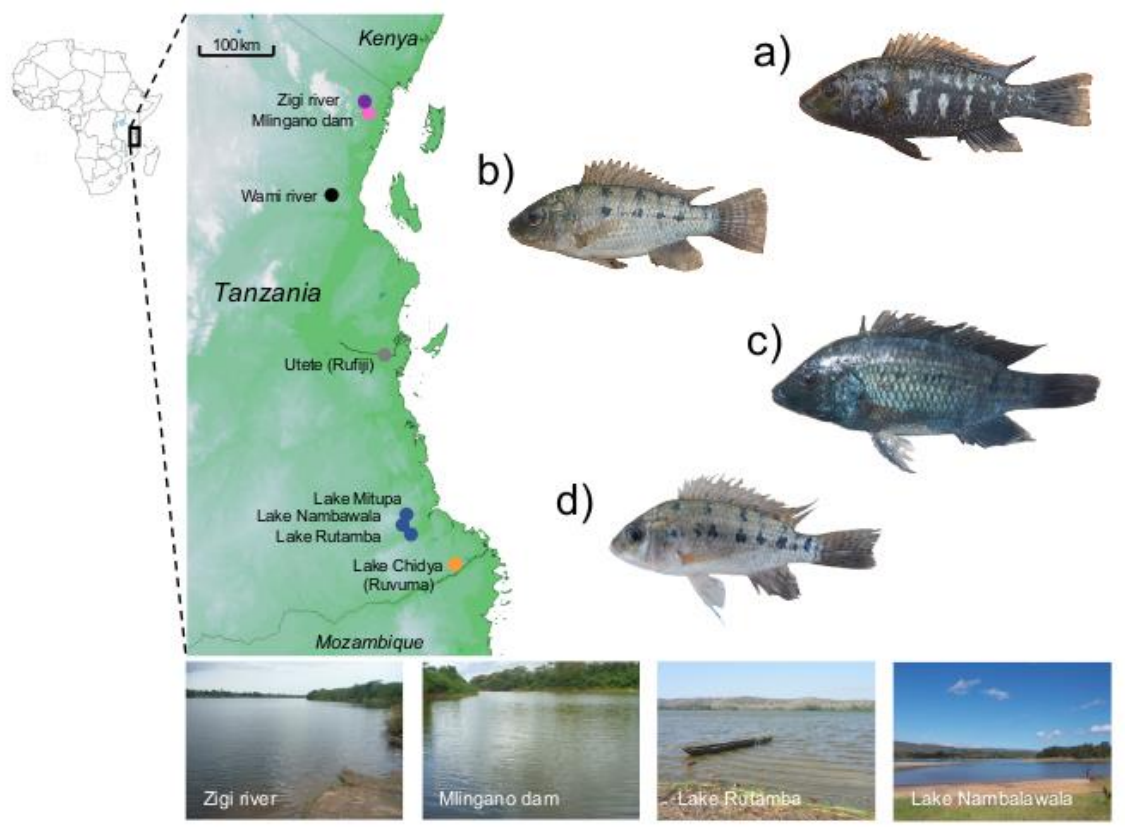

Figure 1. Sampling sites and example specimens of focal populations. a) northern $O$. korogwe male, b) northern $O$. korogwe female, c) southern $O$. korogwe male, d) southern $O$. korogwe female. Pink and purple filled circles indicate northern $O$. korogwe populations sampled, darker blue filled circles locations of the southern $O$. korogwe populations sampled. Grey and black filled circles indicate the sampling locations of $O$. urolepis (Wami and Rufiji and rivers, respectively). The orange filled circles indicate the sampling location of $O$. placidus (Lake Chidya).

Other samples used for this study were O. placidus rovumae from Lake Chidya in the Ruvuma catchment sampled on 18 August 2013, O. placidus rovumae from the Ruvuma river sampled on 16 August 2013, O. placidus rovumae from the Muhuwesi river (Ruvuma drainage) sampled on 17 August 2013, O. urolepis from Lake Lugongwe near Utete on the Rufiji river sampled on 11 March 2015, O. urolepis from Mbuyuni pool on the Wami river sampled on 22 August 2015, and O. niloticus from within its native (rather than introduced) distribution in Lake Albert, Uganda, sampled on 29 October 2015 (Tables S1, S2). Field collected samples were preserved either in 96-100\% ethanol or DMSO salt buffer. 
Table 1. Sample sizes for southern comparison analysis of $O$. korogwe, $O$. niloticus, and individuals of hybrid origin (comparison 1) and comparisons of southern and northern $O$. korogwe populations and reference $O$. urolepis and $O$. placidus (comparison 2).

\begin{tabular}{|c|c|c|c|c|}
\hline Site & Species & Microsatellite & $\begin{array}{l}\text { Linear (conventional) } \\
\text { measures }\end{array}$ & $\begin{array}{l}\text { Geometric } \\
\text { morphometric }\end{array}$ \\
\hline
\end{tabular}

Comparison 1: southern comparison analysis of $O$. korogwe, $O$. niloticus, and hybrids

\begin{tabular}{|c|c|c|c|c|}
\hline \multirow[t]{3}{*}{ Lake Mitupa } & O. korogwe (M-OK) & 2 & - & - \\
\hline & O. niloticus (M-ON) & 3 & 3 & 3 \\
\hline & Hybrid (M-OK x M-ON) & 2 & 1 & 1 \\
\hline \multirow[t]{3}{*}{ Lake Rutamba } & O. korogwe (R-OK) & 17 & 9 & 9 \\
\hline & O. niloticus $(\mathrm{R}-\mathrm{ON})$ & 13 & 6 & 6 \\
\hline & Hybrid (R-OK x R-ON) & 2 & 2 & 2 \\
\hline \multirow[t]{3}{*}{ Lake Nambawala } & O. korogwe (N-OK) & 10 & 9 & 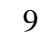 \\
\hline & O. niloticus $(\mathrm{N}-\mathrm{ON})$ & 6 & 4 & d \\
\hline & Hybrid (OK x ON) & 6 & 5 & 5 \\
\hline
\end{tabular}

Comparison 2: southern and northern $O$. korogwe populations, and reference species

\begin{tabular}{llccc} 
Mlingano dam & O. korogwe $(\mathrm{Ml}-\mathrm{OK})$ & 40 & 34 & 40 \\
Zigi River & O. korogwe $(\mathrm{Z}-\mathrm{OK})$ & 16 & 23 & - \\
Lake Chidya & O. placidus $(\mathrm{C}-\mathrm{OP})$ & 10 & - & - \\
Rufiji River & O. urolepis $(\mathrm{RR}-\mathrm{OU})$ & 26 & - & 10 \\
Lake Nambawala & O. korogwe $(\mathrm{N}-\mathrm{OK})$ & 10 & 9 & 9 \\
Lake Rutamba & O. korogwe $(\mathrm{R}-\mathrm{OK})$ & 17 & 14 & 9 \\
\hline
\end{tabular}

\section{Population genetics - microsatellite genotyping}

DNA was extracted from fin clips using the Wizard kit from Promega (Madison, WI). Samples were genotyped at 13 microsatellite loci (Table S3), sourced from Saju et al. (2010) and Liu et al. (2013), within two multiplex reactions for each sample. The first contained 6 loci and the second 7 loci. Polymerase Chain Reaction (PCR) was performed using solutions comprising: $1 \mu \mathrm{l} \mathrm{DNA}, 0.2 \mu \mathrm{l}$ of each $10 \mu \mathrm{M}$ forward primer, $0.2 \mu \mathrm{l}$ of each $10 \mu \mathrm{M}$ reverse primer, $5 \mu \mathrm{l}$ 2x Qiagen Multiplex PCR Master Mix, and made up to $10 \mu \mathrm{l}$ using RNase-free water. PCR was conducted on a 3PRIME X/02 thermocycler (Techne), with the following settings: an initial denaturation at $95^{\circ} \mathrm{C}$ for 60 seconds, followed by 35 cycles of $94^{\circ} \mathrm{C}$ for 30 seconds, $57^{\circ} \mathrm{C}$ for 90 seconds, and $72^{\circ} \mathrm{C}$ for 60 seconds. The final extension stage was $60^{\circ} \mathrm{C}$ for 30 minutes. Products were genotyped on an Applied Biosystems 3500 Genetic Analyser alongside a LIZ500 size standard. Peaks were identified automatically using the software Genemapper v4.1 (Applied Biosystems; CA) and checked manually for accuracy. Arlequin v3.5 (Excoffier and Lischer, 2010) was used to summarize genetic diversity of populations and test for deviations from Hardy Weinberg Equilibrium.

\section{Population genetics - microsatellite evidence of hybridization in the southern lakes}

Potential hybrid individuals between $O$. korogwe and $O$. niloticus were identified from microsatellite data using a two-step process. 1) For all three lakes simultaneously, the find.clusters function in the $\mathrm{R}$ package adegenet v2.1.1 (Jombart and Ahmed 2011) was applied, selecting max.n.clust $=40$, and the 
maximum number of principal components, to make a preliminary assignment of individuals to two genetic clusters $(K=2)$, representing $O$. korogwe and $O$. niloticus. 2) Structure v2.3.4 (Pritchard et al. 2000) was used to quantify probability of assignment of individuals to the two species. Structure runs used $K=2$ with the adegenet find.clusters assignments as a prior. The admixture model was used, with each run including 100,000 steps as burn-in, followed by 100,000 sampled steps. Runs were repeated a total of 10 times, and Structure results were summarized across the runs using Clumpak (Kopelman et al. 2015), with putatively purebred individuals identified as those possessing $>0.9$ probability of belonging to either $O$. korogwe or $O$. niloticus, and the remainder considered to be putative $O$. niloticus $\mathrm{x}$ korogwe hybrids. To ordinate the genetic structure present within the southern lakes, a Factorial Correspondence Analysis in Genetix v4.05 was used (Belkhir et al. 1999).

\section{Population genetics - microsatellite differences between northern and southern O. korogwe.}

The genetic structure of putative purebreds from the southern $O$. korogwe populations (Lake Nambawala and Lake Rutamba) to the northern $O$. korogwe populations (Zigi River and Mlingano Dam) was compared, as well as O. placidus (Lake Chidya) and O. urolepis (Rufiji river at Utete) (Table S4). Oreochromis korogwe individuals from Lake Mitupa were not included in the analysis due to the small sample size of purebred individuals $(n=6)$. Structure v2.3.4 (Pritchard et al. 2000) was used to assess population genetic structure, using sampling location as a prior. The admixture model was selected, with each run including 100,000 steps as burn-in, followed by 100,000 sampled steps. Runs for each potential number of clusters $K$ (between 2 and 6), were repeated a total of 10 times, and the results were summarized using Clumpak (Kopelman et al. 2015). Within Clumpak the Evanno method (Evanno et al. 2005) was used to identify the optimal number of clusters present in the data. A Factorial Correspondence Analysis in Genetix 4.05 was used to ordinate the genetic structure (Belkhir et al. 1999). Genetic structure among the populations was estimated in Genepop v4.2 (Rousset, 2008) using $F_{\text {ST }}$ and the significance of differences among populations was estimated using Exact tests with default settings.

\section{Whole genome resequencing - library preparation and data analysis}

Twelve samples were processed for whole genome resequencing, comprising two $O$. niloticus specimens, two $O$. urolepis specimens, two $O$. placidus specimens, three specimens from a northern $O$. korogwe population (Mlingano Dam) and three specimens from a southern $O$. korogwe population (Lake Nambawala) (Tables S1 and S2). The selection of these specimens was based on phenotypic characters, and they were all assumed to be purebred at the time of selection for WGS analysis. DNA was extracted from fin clips using a PureLink Genomic DNA extraction kit (ThermoFisher, MA, USA). Genomic libraries were prepared using the Illumina TruSeq HT paired-end read protocol, by Earlham Institute Pipelines department. Samples were sequenced using an Illumina HiSeq 2500 with version 4 chemistry (10 samples per lane; target $5 \mathrm{X}$ coverage per sample) and a 125bp paired end read metric. Initial data handling and quality analysis included demultiplexing and conversion to FASTQ files, followed by use of FASTQC (Andrews, 2010) for quality analysis of FASTQ files.

\section{Whole genome resequencing - Read mapping and SNP calling}

Reads were mapped against the "GCF_001858045.2" reference Oreochromis niloticus assembly (Conte et al. 2019) from NCBI, using the default settings of BWA-MEM v0.7.17 (Li 2013), with the output bam files subjected to samtools v1.9 (Li et al. 2009) fixmate prior to being sorted by co-ordinate. Duplicate reads were then marked using picardtools (v1.140; http://broadinstitute.github.io/picard). SNPs were then called using gatk (v4.1.6.0) (McKenna et al. 2010). First, HaplotypeCaller was used on each sample, using min-pruning 1, min-dangling-branch-length 1 and heterozygosity 0.01 . All samples were collated using GenomicsDBImport, before joint-genotyping with GenotypeGVCFs. SNPs within 5 base pairs of an indel were removed using BCFtools v1.10.2, and then SNPs with total depth exceeding 180 (average exceeding 15x coverage per sample), quality-by-depth less than 2, FS greater than 10, MQ less than 30, MQRankSum less than -2, ReadPosRankSum less than -2 or SOR greater than 3 were filtered using GATK VariantFiltration (Table S5). Individual genotypes with depth less than 3 were 
bioRxiv preprint doi: https://doi.org/10.1101/2020.08.06.240002; this version posted August 7, 2020. The copyright holder for this preprint (which was not certified by peer review) is the author/funder, who has granted bioRxiv a license to display the preprint in perpetuity. It is made available under aCC-BY 4.0 International license.

replaced with a no-call. BCFtools v1.10.2 was then used to remove sites which overlapped with indels in some samples, and remove SNPs which fell in scaffolds other than the inferred linkage groups.

\section{Whole genome resequencing - PCA, ADMIXTURE and phylogenetic analysis}

For PCA and ADMIXTURE analysis, biallelic SNPs within the linkage groups, with a minor-allele count of at least 3 and less than $25 \%$ missing taxa per site were extracted. These were filtered for linkagedisequilibrium using PLINK v2.0.0 (Purcell et al. 2007), removing SNPs with $r^{2}>0.2$ in sliding windows of 50 SNPs, with 10 SNP overlap. PCA analysis on the resulting 160,883 SNPs was then carried out in PLINK, with the top 20 principal components reported. To investigate population membership, we used Bayesian clustering in ADMIXTURE v1.3.0 (Alexander et al. 2009) on the same SNP dataset. which uses a similar algorithm to the Structure program used for the microsatellite analysis, but runs more quickly on large datasets. ADMIXTURE analysis was run using the main algorithm, from $K=1$ to $K=6$, with default values for cross-validation error estimation.

For the nuclear phylogeny, SNPs with at least one homozygous reference and one homozygous alternate site were extracted. A phylogenetic tree was inferred using RAxML v8.0.20 (Stamatakis 2014) and the GTRGAMMA model of evolution, with the lewis ascertainment bias correction and 200 rapid bootstraps. To examine the mitochondrial phylogeny, de novo assemblies were produced from the raw reads for each individual, using mtArchitect (Lobon et al. 2016), which accounts for nuclear mitochondrial DNA segments. These assemblies were aligned using MAFFT v7.271 (Katoh and Standley 2013). A phylogenetic tree was then inferred using RAxML, the GTRGAMMA model of evolution and 200 rapid bootstraps.

\section{Whole genome resequencing - differentiation across the genome}

Relative genetic differentiation between populations (Weir and Cockerham $F_{\mathrm{ST}}$ ) as well as absolute sequence divergence within (pi) and between (Dxy) populations were calculated in non-overlapping $50 \mathrm{~kb}$ windows using popgenWindows.py (https://github.com/simonhmartin/genomics_general). For this analysis, SNPs were filtered to include only sites with at least two individuals per population. Both pi and Dxy require counts of all sites in a window, including SNPs and monomorphic sites. To get the number of callable sites across the genome, we used the CallableLoci function within GATK v3.7.0 (McKenna et al. 2010) and a custom script to get counts in each 50kb window. Inferred values of Dxy and pi from popgenWindows.py were then corrected to account for monomorphic sites, which were not in the input vcf, by multiplying them by the number of SNPs in the windows, and then dividing by the total number of callable sites. The $O$. placidus samples were not included as one specimen was evidently a hybrid (see Results).

We also used Twisst (Martin and Van Belleghem 2017) to explore phylogenetic relationships across the genome. Although we did not perform phasing and imputation for the main whole genome dataset analysis due to the small sample size, it is useful for phylogenetic analysis and likely to be accurate over the short (50-SNP) regions considered in the Twisst analysis (discussed further in Martin \& Belleghem 2017). We therefore first performed phasing and imputation of biallelic SNPs with minor-allele count of at least three and less than 3 missing taxa using Beagle v4.1 (Browning and Browning 2007) with a window size of 10,000 and overlap of 1000 SNPs. Phylogenetic trees were inferred over sliding 50-SNP windows (requiring at least 40 SNPs per individual), with a 10 SNP overlap using IQtree v1.6.12 (Nguyen et al. 2015) using the best fit model for each, with ascertainment bias correction, using scripts modified from genomics_general (https://github.com/simonhmartin/genomics_general).. We then ran Twisst to calculate topology weightings for each window using the method 'complete'. A smoothing parameter was applied with a loess span of 500,000 base pairs, with a 25,000 spacing.

\section{Divergence times}

We used estimates of Dxy to estimate divergence times between korogwe from Mlingano, and Nambawala. To convert estimates of Dxy to divergence times, we used the genome-wide mutation $(\mu)$ estimate of $3.5 \times 10^{-9}\left(95 \%\right.$ confidence interval: $1.6 \times 10^{-9}$ to $\left.4.6 \times 10^{-9}\right)$ per bp per generation as 
recently estimated for haplochromine cichlids in Malinsky et al. (2018) and assumed a generation time of one year. This was chosen because studies of wild populations of Oreochromis species suggest that generation time varies from 3-36 months and is dependent on habitat and population density, with populations in shallow-water and inshore habitats maturing at 12 months or less (Lowe-McConnell 1982). Given the small adult body size of $O$. korogwe and its occurrence in shallow eutrophic water bodies, we used a generation time at the lower end of this range of 1 year.

Estimates of Dxy between the Mlingano and Nambawala korogwe will be increased in genomic regions involved with introgression or incomplete lineage sorting. Using the Twisst output, we identified windows where the weighting of the species tree was 1, i.e. there is no evidence for discordance. Using bedtools (v2.28.0) (Quinlan and Hall 2010), we found the 50kb windows overlapping these regions, and used Dxy from these regions to get a measure of divergence in windows supporting the species tree.

\section{D3 statistics}

The genotypes used for sliding window $F_{\mathrm{ST}}$, Dxy and pi analysis were using to calculate pairwisedistances between each individual, in 50kb non-overlapping windows across the genome, using distMat.py (https://github.com/simonhmartin/genomics_general). This pairwise-distance was corrected using the number of callable sites per window (see that section of the methods). D3 statistics can be used to test for introgression between either P3 and P2 or P3 and P1 in a three-taxon phylogeny $(\mathrm{P} 3,(\mathrm{P} 2, \mathrm{P} 1))$; , without the presence of an outgroup, using genetic distances. Introgression would be expected to result in reduced genetic distance between the two taxon in question. Using the equation $D 3=(d \mathrm{P} 1 \mathrm{P} 3-d \mathrm{P} 2 \mathrm{P} 3) /(d \mathrm{P} 1 \mathrm{P} 3+d \mathrm{P} 2 \mathrm{P} 3)$; where $d \mathrm{P} 1 \mathrm{P} 3$ is the distance between $\mathrm{P} 1$ and $\mathrm{P} 3$ and $d \mathrm{P} 2 \mathrm{P} 3$ is the distance between $\mathrm{P} 2$ and $\mathrm{P} 3$, a result where $D 3$ is significantly less than 0 indicates introgression between $\mathrm{P} 1$ and $\mathrm{P} 3$, whereas a result where $D 3$ is significantly greater than 0 indicates introgression between P2 and P3 (Hahn and Hibbins 2019). Significance was assessed by 1000 block bootstrap replicates, with the standard deviation used to calculate $\mathrm{p}$ values using the overall mean $D 3$. The test was carried out between all trios of species where P1 was an individual from $O$. korogwe Nambawala, P2 was an individual from $O$. korogwe Mlingano and P3 was an individual from either Oreochromis niloticus or Oreochromis urolepis.

\section{Geometric morphometrics - analyses of individuals from the southern lakes}

Ethanol preserved specimens were photographed on their left side in standard orientation with a scale. The image was calibrated for size and 24 landmarks (Fig. S1) were placed onto the image of each specimen using tpsDIG 1.40 (Rohlf, 2004). All microsatellite-genotyped fish (See below) were included in geometric morphometrics, except for specimens of $O$. korogwe where pelvic fins were naturally absent. Landmark data were subjected to a Procrustes analysis in MorphoJ 1.06 (Klingenberg, 2011). Individuals were assigned to one of three groups based on Structure results (purebred O. niloticus, purebred $O$. korogwe, hybrid $O$. niloticus x korogwe). The Procrustes coordinates were then regressed against centroid size in MorphoJ 1.06, and the size standardized residuals from this regression analysis were then used in a stepwise Discriminant Analysis in SPSS 24 (IBM, London), with purebred $O$. niloticus and purebred $O$. korogwe placed in a-priori known categories, and hybrid individuals uncategorized.

Linear morphometric measurements were taken from each genotyped specimen collected in 2016 using digital calipers, following methods outlined in Barel et al. (1977) and Snoeks (2004). The following measures were made: standard length, body depth, head length, caudal peduncle length, caudal peduncle depth, dorsal fin base length, anal fin base length, pectoral fin base length, pelvic fin length, caudal fin length, head width, snout length, eye length, interorbital width and lower jaw length. Measurements were $\log _{10}$ transformed and size-standardized residuals generated from a linear regression against standard length. Individuals were assigned to the three different groups based on Structure results (purebred $O$. niloticus, purebred $O$. korogwe, hybrid $O$. niloticus x korogwe). The size-standardized residuals were used in a Discriminant Analysis in SPSS 24 (IBM, London), with purebred O. niloticus 
and purebred $O$. korogwe placed in a-priori known categories, and hybrid individuals remaining uncategorized.

\section{Morphological comparisons between northern and southern O. korogwe}

The morphology of genetically purebred $O$. korogwe from Lakes Rutamba and Nambawala (identified from microsatellite data) was compared to individuals from the Mlingano Dam and Zigi River in northern Tanzania. Geometric morphometric landmarks and linear morphometric measurement data were collected using the methods described above. The geometric morphometric landmarks were subjected to a Procrustes standardization and the resultant Procrustes coordinates were subjected to a pooled within-group regression against centroid size, generating size standardized residuals. These residuals were used in a Canonical Variates Analysis in MorphoJ 1.06, and a Discriminant Analysis in SPSS 24. Linear morphometric measurements were $\log _{10}$ transformed. A small number (9 of 2000) of measurements were interpolated using Bayesian PCA in the R package pcaMethods (Stacklies et al. 2007), allowing individuals with absent pelvic fins or damaged fins to be included in analyses. We then pooled within-group regressions of each variable against standard length, treating each of the four populations as a group. The size-standardized residuals generated from these regressions were then used in a Discriminant Analysis in SPSS 24.

\section{Results}

\section{Population genetics - microsatellite analysis of purebred and hybrid Oreochromis in southern lakes}

Using Structure, the majority of individuals were assigned to one of the two parent species with a probability of $>90 \%$. Individuals that were not able to be assigned to a single species with a probability of $>90 \%$ were considered hybrids. In total these hybrids comprised $29 \%$ of individuals sampled from Lake Mitupa ( 2 of 7), 27\% of individuals from Lake Nambawala (6 of 22), and 6\% of individuals from Lake Rutamba (2 of 32) (Fig. 2a,b).

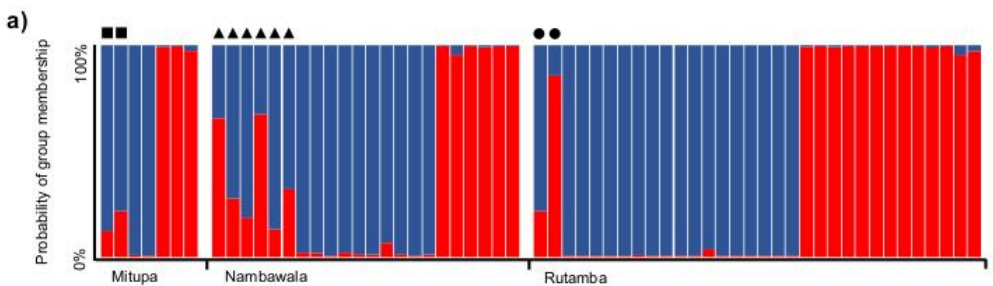

b)

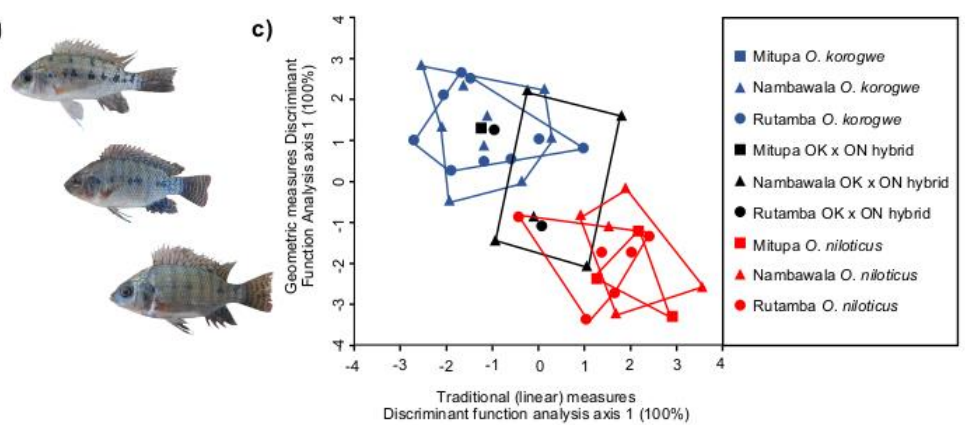

Figure 2. Genetic and morphological contrasts between $O$. korogwe, O. niloticus and $O$. korogwe x niloticus hybrids. a) Structure assignment of individuals to populations $(K=2)$ using microsatellite data from Oreochromis from the southern lakes. Filled black symbols indicate individuals of putative hybrid origin. b) images of $O$. korogwe (top), O. korogwe x niloticus (middle) and O. niloticus (bottom). c) Discriminant function axes illustrate distinctive morphology of purebred $O$. korogwe (blue)s and $O$. niloticus (red) O. korogwe $x$ niloticus hybrid individuals which overlap in morphospace with parent taxa. 
a)

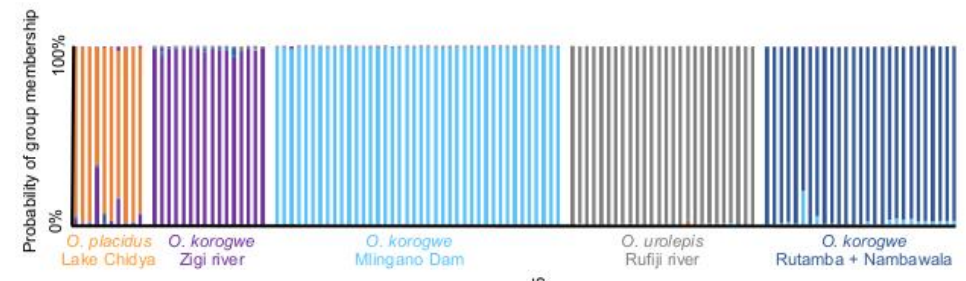

b)

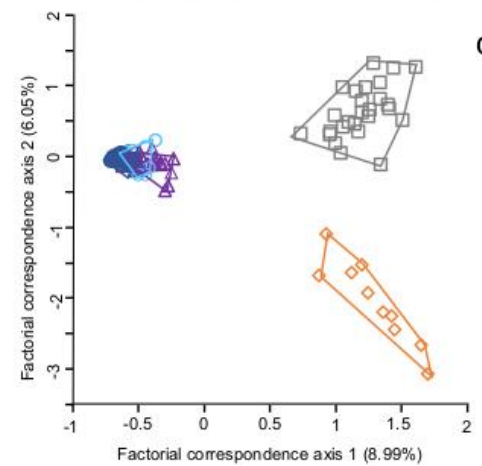

d)

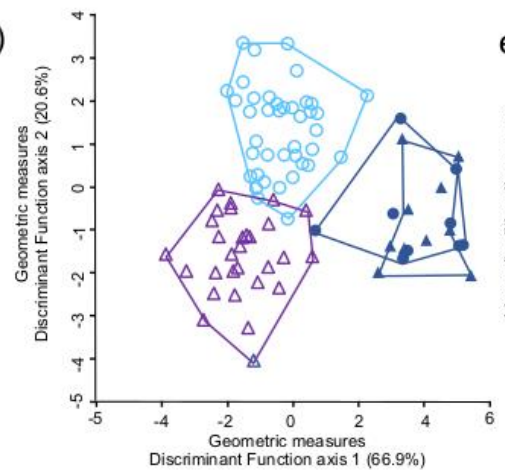

c)
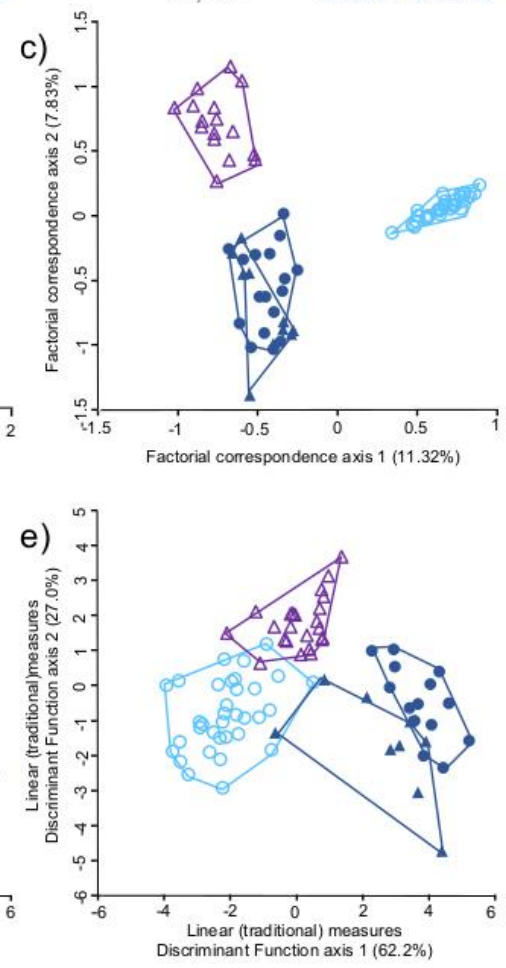

f)

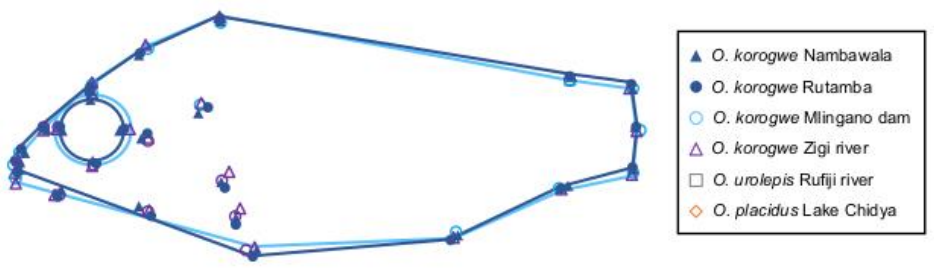

Figure 3. Genetic and morphological analysis of focal populations of $O$. korogwe, and reference populations of O. urolepis (Utete), and O. placidus (Lake Chidya). a) Structure analysis of the six populations, using $K=5$. b) Factorial correspondence analysis (FCA) of all populations from all six sites, c) FCA of the four O. korogwe populations, d-e) Discriminant Function analysis (DFA) of the four O. korogwe populations using linear and geometric measures respectively, and f) Wireframe analysis from Canonical Variates Analysis (CVA) showing geometric morphometric divergence between northern (light blue lines) and southern (dark blue lines) populations.

\section{Morphological comparisons of purebred and hybrid Oreochromis in southern lakes}

Discriminant Analysis of geometric morphometric data demonstrated that $O$. niloticus and $O$. korogwe individuals could be reliably separated (Wilk's $\lambda=0.272, \chi^{2}=37.054, P<0.001$ ) with 30 of 32 purebred individuals correctly classified (Table S6). Equally, Discriminant Analysis using linear morphometric measurements showed that that $O$. niloticus and $O$. korogwe individuals could be reliably separated (Wilk's $\lambda=0.314, \chi^{2}=32.401, P<0.001$ ), with 29 of 32 purebred individuals correctly classified (Table S6). Typically, $O$. niloticus were characterized as possessing a longer and broader head (Table S7). Hybrid morphospace overlapped with that of purebred species in both datasets (Fig. 2c). 


\section{Population genetics - microsatellite genetic structure among Oreochromis populations}

Structure analyses indicated the optimum number of genetically distinct populations across the six sampled populations was $K=5$, with the southern populations from neighbouring lakes Rutamba and Nambawala resolved as genetically homogeneous group (Fig 3a). All O. korogwe were genetically distinct from reference populations of $O$. urolepis from the Rufiji river and $O$. placidus from Lake Chidya in ordination plots (Fig. 3b). Analysis including only $O$. korogwe revealed the Zigi river and Mlingano dam populations to be distinct from one another, and to both populations from the south (Fig. 3c). In pairwise comparisons, all populations showed highly significant genetic differences, with exception of $O$. korogwe from Lakes Rutamba and Nambawala (Table 2). No populations showed clear patterns of significant deviation from Hardy-Weinberg Equilibrium in microsatellite loci (Table S4).

Table 2. Matrix of $F_{\text {ST }}$ pairwise comparisons (below left) and corresponding $P$ values from Exact tests (above right).

\begin{tabular}{|c|c|c|c|c|c|c|}
\hline & $\begin{array}{l}\text { O. placidus } \\
\text { Chidya }\end{array}$ & $\begin{array}{c}\text { O. korogwe } \\
\text { Zigi }\end{array}$ & $\begin{array}{l}\text { O. korogwe } \\
\text { Mlingano }\end{array}$ & $\begin{array}{l}\text { O. urolepis } \\
\text { Rufiji }\end{array}$ & $\begin{array}{c}\text { O. korogwe } \\
\text { Rutamba }\end{array}$ & $\begin{array}{l}\text { O. korogwe } \\
\text { Nambawala }\end{array}$ \\
\hline O. placidus Lake Chidya & & $<0.001$ & $<0.001$ & $<0.001$ & $<0.001$ & $<0.001$ \\
\hline O. korogwe Zigi river & 0.547 & & $<0.001$ & $<0.001$ & $<0.001$ & $<0.001$ \\
\hline O. korogwe Mlingano dam & 0.761 & 0.341 & & $<0.001$ & $<0.001$ & $<0.001$ \\
\hline O. urolepis Rufiji river & 0.229 & 0.455 & 0.612 & & $<0.001$ & $<0.001$ \\
\hline O. korogwe Lake Rutamba & 0.659 & 0.358 & 0.378 & 0.511 & & 0.473 \\
\hline O. korogwe Lake Nambawala & 0.618 & 0.415 & 0.470 & 0.461 & 0.011 & \\
\hline
\end{tabular}

\section{Morphological comparisons of northern and southern O. korogwe}

Discriminant Function Analysis of both the geometric morphometric data and the traditional morphometric data demonstrated highly significant differences between the northern and southern $O$. korogwe groups (Fig. 3d,e), with the majority of individuals being able to be classified by sampling site using either linear traditional measurement data (74 of 80 individuals), or geometric morphometric data (84 of 88 individuals; Table S8). Discriminant Function Axis 1 separated northern and southern populations in both morphological datasets. In the linear measurements this axis indicated $O$. korogwe from the northern populations to have shallower body depth, a less deep caudal peduncle, a narrower interorbital width and shorter pectoral fins, relative to southern populations (Table S9). Wireframe diagrams indicated northern $O$. korogwe populations had smaller eyes and shallower body dimensions than southern populations (Fig. 3f).

\section{Whole genome resequencing: phylogenomic analyses}

Illumina sequencing resulted in an average of 22 million reads per sample (range: 20.53 to 24.40 million), and mapping rates to the O. niloticus reference genome of 97.39 to $99.18 \%$ (Table S1). Mean sequencing coverage across the dataset was 5.29X, with approximately half the genome covered with a sequencing depth of at least $5 \mathrm{X}$ (Table S1). The filtered datasets and number of SNPs used for downstream analysis are given in Table S10. ADMIXTURE analysis of all 12 samples suggested crossvalidation minima at $K=2$ and $K=5$, indicating the most likely number of clusters in the dataset (Fig. S2). At $K=5$, there was a clear separation of the northern and southern $O$. korogwe populations alongside the other species, supported by groupings in PCA (Fig. 4a). The ADMIXTURE analysis also indicated that one $O$. placidus sample was likely an early-generation $O$. placidus $x$ niloticus hybrid or backcross, with approximately $40 \%$ O. niloticus cluster membership (Fig. 4b).

Maximum likelihood phylogenetic analysis indicated that the $O$. placidus hybrid was likely the result of a female $O$. niloticus x male $O$. placidus cross, as the (maternally inherited) mtDNA of the sample 
bioRxiv preprint doi: https://doi.org/10.1101/2020.08.06.240002; this version posted August 7, 2020. The copyright holder for this preprint (which was not certified by peer review) is the author/funder, who has granted bioRxiv a license to display the preprint in perpetuity. It is made available under aCC-BY 4.0 International license.

clustered with $O$. niloticus (Fig. 4d). Otherwise, there was a clear separation of $O$. urolepis, $O$. niloticus, $O$. placidus and the two $O$. korogwe populations in both the nuclear and mtDNA phylogenies (Fig. 4cd).

a)

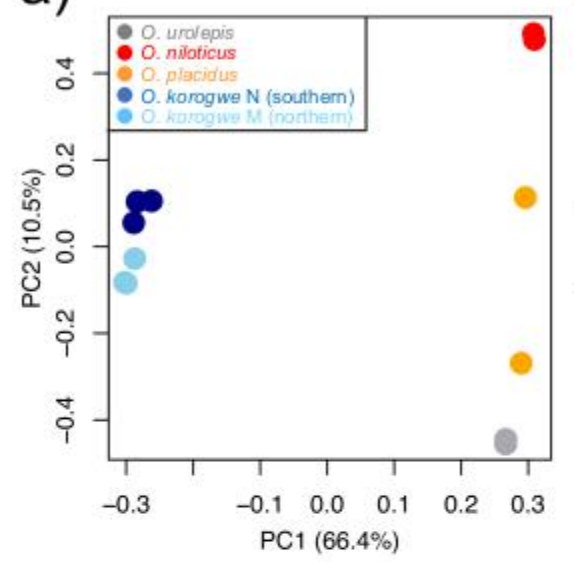

c)

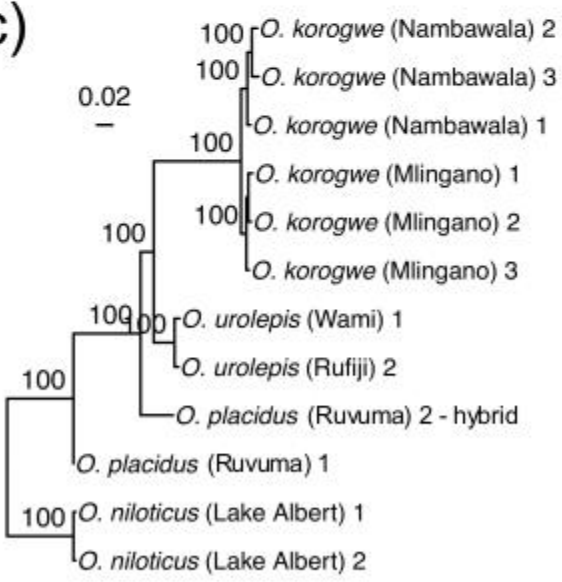

b)

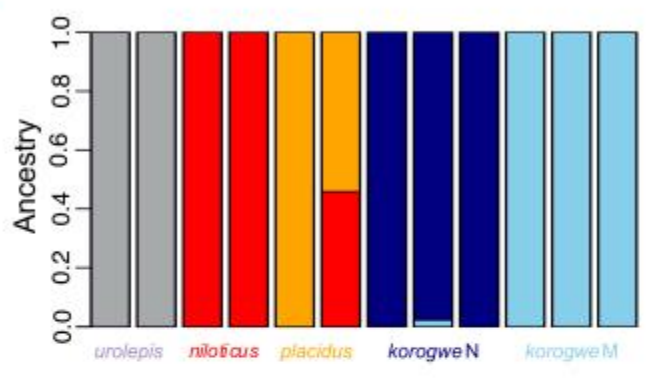

d)

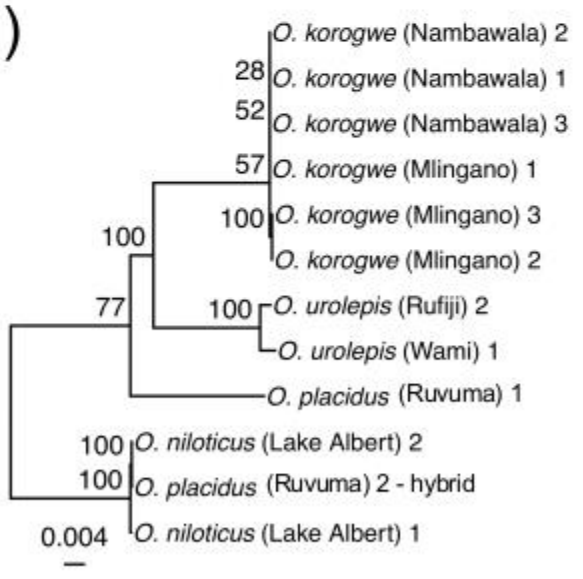

Figure 4. Analyses of genome-wide data. a) Principal Component Analysis (PCA) of all variants, b) Admixture analysis of all variances, c) phylogeny based on nuclear genome variants, using RAxML GTR+ $\Gamma$ model. d) phylogeny based on mitochondrial genome variants, using RAxML GTR $+\Gamma$ model. Scale bars in changes per bp. Values on nodes indicate bootstrap support values for 1000 bootstraps, those $>70 \%$ shown.

Differentiation $\left(F_{\mathrm{ST}}\right)$ was highest among interspecific comparisons (Fig. 5a-f). Between the northern (Mlingano Dam) and southern (Nambawala) O. korogwe populations, most $50 \mathrm{~kb}$ windows had low differentiation, but there were prominent regions of the genome showing very high $F_{\mathrm{ST}}$ differentiation (Fig. 5e). Notably, there were regions of relatively low genetic differentiation between the $O$. niloticus and $O$. korogwe sampled from Nambawala where the two species are sympatric (Fig 5f), but these were not apparent in the comparison between the fully allopatric $O$. niloticus and $O$. korogwe from Mlingano Dam (Fig. 5d). Section of low $F_{\mathrm{ST}}$ were also apparent in the comparison of $O$. korogwe from Nambawala and $O$. urolepis. Sections of low $F_{\mathrm{ST}}$ were showed no clear pattern of being associated with areas of elevated or depleted genomic diversity (pi) in the focal species (Fig. S3). However, it was notable that in all species LG3 had substantially higher variability in genetic diversity relative to other linkage 
bioRxiv preprint doi: https://doi.org/10.1101/2020.08.06.240002; this version posted August 7, 2020. The copyright holder for this preprint (which was not certified by peer review) is the author/funder, who has granted bioRxiv a license to display the preprint in perpetuity. It is made available under aCC-BY 4.0 International license.

groups, and possessed higher absolute sequence divergence in both intraspecific and interspecific comparisons (Fig. S4).

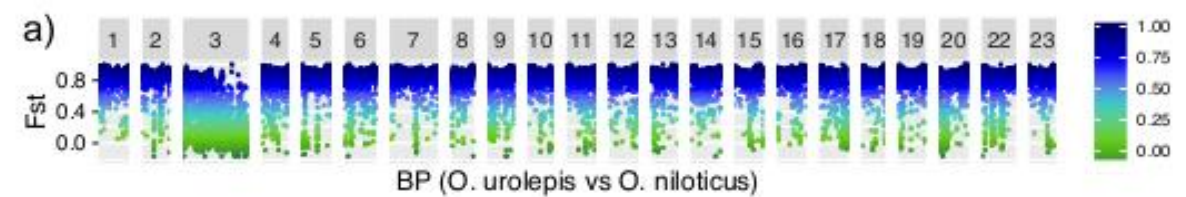

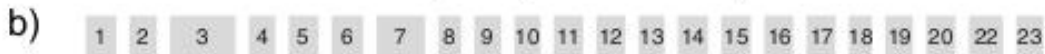

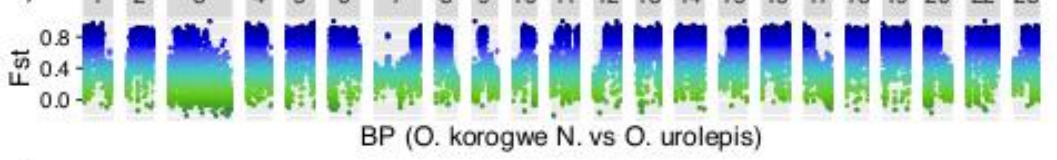

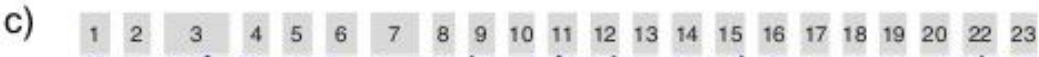

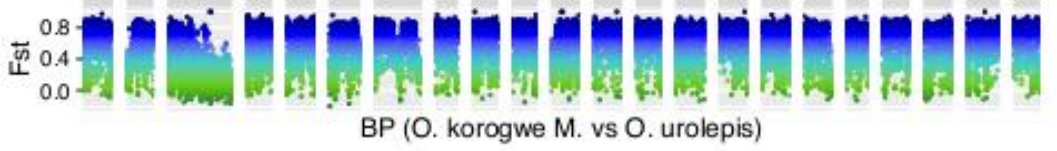

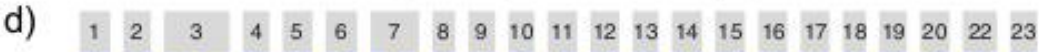

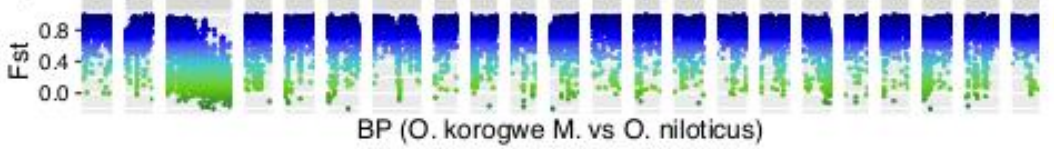

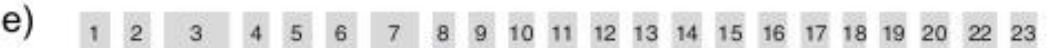

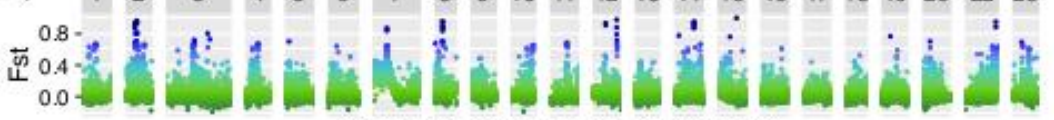

BP (O. korogwe M. vs O. korogwe N.)

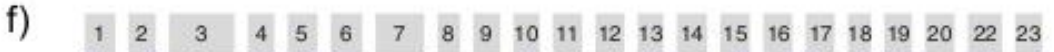
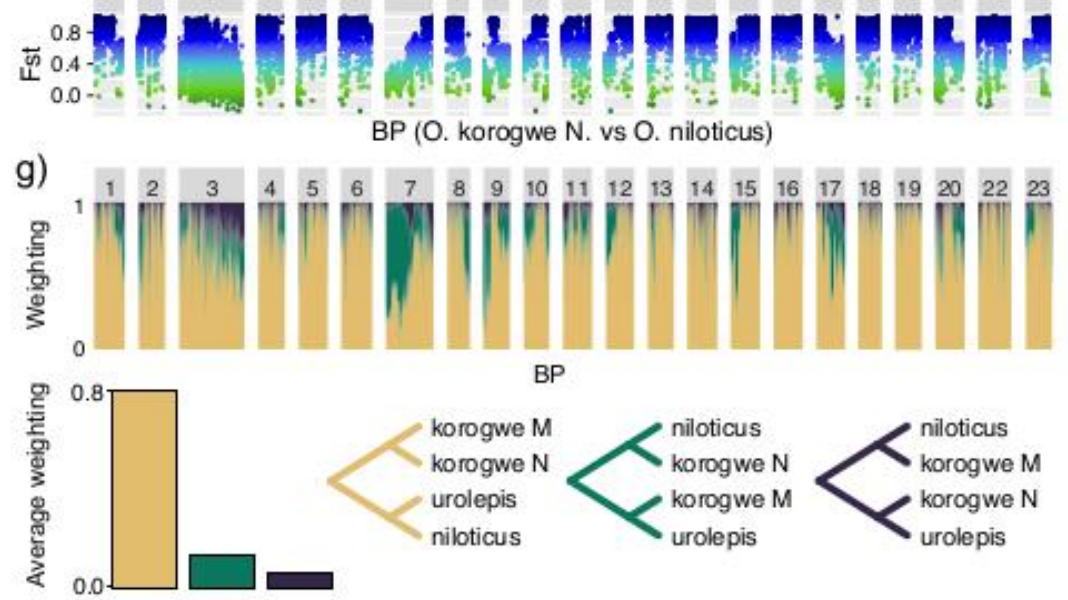

Figure 5. a-f) Pairwise sliding window $F_{\mathrm{ST}}$ between populations across genome linkage groups, in $50-\mathrm{kb}$ windows, between combinations of $O$. niloticus, $O$. urolepis, southern $O$. korogwe $\mathrm{N}$ (Lake Nambawala), northern $O$. korogwe M (Mlingano Dam). g) Phylogenetic representation across genomes of four populations, as estimated by Twisst. Three possible phylogenies for the four taxa are illustrated below, and their colours correspond to relative weightings in plot above. The linkage groups are labelled according to the numbering of the linkage groups in the reference genome. 
bioRxiv preprint doi: https://doi.org/10.1101/2020.08.06.240002; this version posted August 7, 2020. The copyright holder for this preprint (which was not certified by peer review) is the author/funder, who has granted bioRxiv a license to display the preprint in perpetuity. It is made available under aCC-BY 4.0 International license.

\section{Whole genome resequencing: differentiation across the genome and timescale of divergence}

Phylogenetic relationships across the genome, generated using Twisst, provided evidence of admixture that was heterogeneous across the genome (Fig. $5 \mathrm{~g}$ ). The two $O$. korogwe populations were resolved as sister taxa across most of the genome. However, for substantive sections of the genome, a phylogeny supported $O$. niloticus and the southern $O$. korogwe (Nambawala) as sister taxa, and $O$. urolepis and northern $O$. korogwe (Mlingano Dam) as sisters. Notably, these tracts of the genome consistent that are consistent with interspecific hybridization corresponded with both the low $F_{\mathrm{ST}}$ regions $O$. niloticus and the southern $O$. korogwe (Nambawala) (Fig 5f), and low $F_{\mathrm{ST}}$ region between $O$. urolepis and the northern $O$. korogwe (Mlingano) (Fig 5b). D3 statistics consistently provided strong statistical support for scenarios of both decreased genetic distance between $O$. niloticus and southern $O$. korogwe in Nambawala compared to between $O$. niloticus and northern $O$. korogwe, and between $O$. urolepis and the northern $O$. korogwe at the Mlingano Dam compared to between $O$. urolepis and southern $O$. korogwe (Table S11).

Overall absolute sequence divergence (Dxy) between the northern (Mlingano Dam) and southern (Nambawala) O. korogwe populations was 0.0009 (Fig. S5). Applying the genome-wide mutation $(\mu)$ rate estimate of $3.5 \times 10^{-9}$ (95\% confidence interval: $1.6 \times 10^{-9}$ to $4.6 \times 10^{-9}$ ) from Malinsky et al. (2018), with a generation time of one year, gave a genome-wide divergence time estimate of $271 \mathrm{KYA}$ (95\% CI: 206-594 KYA). Using only those regions of the genome consistent with the hypothesis of the northern and southern $O$. korogwe being sister taxa, the overall absolute sequence divergence (Dxy) was 0.0005, providing a divergence time estimate of 144 KYA (95\% CI: 109-315 KYA).

\section{Discussion}

\section{Population structure of southern and northern O. korogwe.}

This study confirmed the distinctness of all sampled $O$. korogwe populations from two other species of Oreochromis naturally present in coastal rivers of Tanzania, namely $O$. placidus and $O$. urolepis. The results also demonstrated a close evolutionary relationship between $O$. korogwe individuals in northern and southern Tanzania. Nevertheless, there has been extensive morphological divergence between the northern and southern $O$. korogwe, and based on least admixed sections of the genome, this divergence took place approximately 140,000 years ago. Therefore, the data are consistent with these taxa representing independent evolutionarily significant units. The presence of a $500 \mathrm{~km}$ gap between the sampled northern and southern populations of $O$. korogwe in Tanzania, is intriguing. In tilapiine cichlids the presence of such gaps is typically due to human intervention. For example, stocking has resulted in $O$. niloticus having a broad discontinuous distribution across Africa, and further afield (Deines et al. 2014). However, our results are consistent with the current distribution of $O$. korogwe being natural. The distribution may have arisen from a natural long-distance colonization event, or perhaps that the species once had a wider distribution that has been disrupted through either extirpation or introgression with $O$. urolepis, a species that neatly fits the gap between northern and southern $O$. korogwe (Ford et al. 2019; Shechonge et al. 2019).

\section{Morphological variation among $O$. korogwe populations}

Our results showed that the northern and southern $O$. korogwe populations are largely distinct in characters such as body depth, fin length and eye size morphology. The populations are sufficiently divergent in morphology to warrant consideration of these as distinct species under morphological species concepts. The anatomical divergence may be accompanied by ecological differences, as variation in craniofacial morphology and body shape are often related to resource use patterns in cichlids. For example, variation in eye size is related to visual environment (Hahn et al. 2017), and fin morphology is related to patterns of habitat use (Colombo et al. 2016). Little is known about the feeding habits of $O$. korogwe and detailed analysis of diets and foraging environments within the sampled locations are required to explore functions of the morphological variation observed. Given the allopatric nature of the populations, further ecologically and developmentally-focussed work would also help to 
reveal if the observed divergence can be attributed to fixed genetic differences, or alternatively variation between environments during development (Parsons et al. 2011; Schneider and Meyer, 2017).

Our microsatellite-based results also confirmed the presence of hybrids between $O$. korogwe and invasive $O$. niloticus in all three of the southern lakes, with a frequency of between 6 and 29\% of sampled individuals. This level of hybridization is likely to be an underestimate if purebreds are present (Boecklen \& Howard, 1997), which our genome-wide analyses also support. Such hybridization between native and non-native species commonly occurs when invader is closely-related to the native species, and the species pair are still reproductively compatible due to an absence of strong reproductive barriers that typically isolate naturally sympatric taxa (Horreo et al. 2011, Gainsford, 2014). It is not fully understood what factors influence the extent of reproductive isolation among Oreochromis species. However, it is notable that like many African mouthbrooding cichlids, Oreochromis exhibit traits indicative of sexual selection based on male colours or the characteristics of breeding territory (Trewavas 1983). It is possible that in this case hybridization between $O$. korogwe or $O$. niloticus takes place due to both species possessing dark male breeding colours (Genner et al. 2018). Female mating decisions also biased towards larger individuals in Oreochromis species, most likely due to the influence of male-male competition on breeding territory acquisition (Nelson 1995; Fessehaye et al. 2006). Hence, is also conceivable that larger $O$. niloticus males have effectively excluded smaller $O$. korogwe males from suitable breeding habitats; but detailed survey and experimental work is required to test this hypothesis, including tests of sex-biases in the direction of hybridization (e.g. Hayden et al. 2010; Rognon \& Guyomard, 2003).

\section{Heterogeneity of admixture across the genome}

We conducted genome-wide scans of $F_{\mathrm{ST}}$ and Dxy between $O$. niloticus, $O$. urolepis and $O$. korogwe populations. $F_{\mathrm{ST}}$ between the northern (Mlingano Dam) and southern (Nambawala) O. korogwe populations was typically low across all linkage groups, with peaks of high $F_{\mathrm{ST}}$ that may reflect genomic regions under directional selection. These peaks of the $F_{\mathrm{ST}}$ were not clustered, and these regions associated loci associated with the divergent phenotypes of these populations. These patterns are characteristic of early stage speciation under geographical isolation (Seehausen et al. 2014).

Between $O$. urolepis and $O$. niloticus a consistent pattern of high $F_{\mathrm{ST}}$ was present, reflecting the long divergence. On linkage group $3, F_{\text {Sт }}$ was lower, and but it is notable that this shows an unusually high level of sequence diversity in all our studied Oreochromis populations (Fig. S4), as well as a high level of absolute sequence divergence between all populations (Fig. S5). On account of this linkage group being 2-3 times larger than any other in the Oreochromis genome (Fig. 6; Conte et al. 2019), LG3 has been referred to as a megachromosome, and is likely to consist of a fusion with an ancestral Bchromosome (Conte et al. 2020). It is rich in long-coding RNA, genes related to immune response and regulation, and repetitive elements. It has also been reported as containing a sex-determination locus in Oreochromis, albeit not in $O$. niloticus itself (Conte et al. 2020). Collectively, the high genetic diversity of this linkage group explains the relatively low $F_{\mathrm{ST}}$ observed between $O$. urolepis and $O$. niloticus, and between other species pairs.

In comparisons between $O$. niloticus and southern $O$. korogwe from Lake Nambawala, there was considerable heterogeneity in $F_{\mathrm{ST}}$ across the genome. There were notable long-tracts of relatively low $F_{\mathrm{ST}}$, most conspicuously on linkage groups $1,7,910,17,20$ and 23 . Many of these were paralleled by low $F_{\mathrm{ST}}$ between $O$. urolepis and $O$. korogwe from Lake Nambawala. However, the regions of low differentiation were not present in comparisons between $O$. niloticus and northern $O$. korogwe from the Mlingano Dam, or between $O$. urolepis and O. korogwe from the Mlingano Dam. This is suggestive of the observed patterns of substantive genomic heterogeneity being reflective of admixture events in the south of Tanzania, after the split from northern $O$. korogwe approximately 140,000 years ago.

Given our microsatellite evidence of individuals of $O$. korogwe $x$ niloticus hybrid ancestry within Lake Nambawala, tracts of low $F_{\text {ST }}$ between $O$. korogwe $x$ O. niloticus plausibly reflect hybridization between in the southern region. The analysis of phylogenetic relationships of the focal populations in this study 
using Twisst show that although the species tree relationship is most common across the genome, there is a substantial difference in the frequency of the two discordant relationships, which under incomplete lineage sorting alone would be expected to have the same frequency, The observed excess of the discordant topology grouping $O$. niloticus with $O$. korogwe Nambawala and $O$. urolepis with $O$. korogwe Mlingano (green in Figure 5g) therefore suggests introgression between $O$. niloticus and $O$. korogwe Nambawala or between $O$. urolepis and $O$. korogwe Mlingano. Supporting this, all D3 analysis suggest significantly lower genetic distances between $O$. niloticus and $O$. korogwe Nambawala and between $O$. urolepis and $O$. korogwe Mligano, than otherwise expected under a model of nohybridization. However, this three-taxon analysis can be confounded by introgression events involving taxa that have not been included in the analysis. Introgression between $O$. niloticus and $O$. korogwe Nambawala, for example, would increase average the genetic distance between $O$. korogwe Nambawala and $O$. urolepis, as the genetic distance between $O$. urolepis and $O$. niloticus is greater than between $O$. urolepis and $O$. korogwe Nambawala. A single introgression event, between $O$. niloticus and $O$. korogwe Nambawala, could therefore explain both positive results.

The genomic regions of this introgression highlighted by the Twisst analysis overlap with the low $F_{\text {ST }}$ regions between $O$. niloticus and $O$. korogwe Nambawala, but such low $F_{\mathrm{ST}}$ regions are not observed between $O$. urolepis and $O$. korogwe Mlingano. The most congruent interpretation of these $F_{\mathrm{ST}}$ results is introgression between $O$. niloticus and $O$. korogwe Nambawala. The parallel regions of low $F_{\mathrm{ST}}$ present between $O$. korogwe from Lake Nambawala and $O$. urolepis are unusual however, given that $O$. urolepis has never been recorded inside Lake Nambawala, or elsewhere in the known range of $O$. korogwe (Shechonge et al. 2019). One possible explanation for this pattern is that the introduced $O$. niloticus population in Lake Nambawala could itself comprise $O$. urolepis x niloticus hybrids, as these species are known to hybridise elsewhere in Tanzania (Shechonge et al. 2018), and it is plausible that Nambawala was stocked from a hybrid population. Alternatively, these low $F_{\mathrm{ST}}$ tracts may reflect recent admixture of ancestral variation shared by both $O$. urolepis and $O$. niloticus. We have not sequenced the $O$. niloticus from Lake Nambawala to test for the presence of recent introgression with $O$. urolepis, but this may be enlightening. We must also note that the low sample sizes ( $\mathrm{n}=2$ to 3 individuals) will have limited the accuracy and reliability of $F_{\mathrm{ST}}$, Dxy and pi statistics. Further studies with more comprehensive phylogenetic and population sampling with greater sample sizes may be able to untangle the nature of introgression events with more precision.

Extensive heterogeneity in the extent of admixture across genomes has been reported in multiple studies of closely related species, including trees (Wang et al. 2020), insects (Martin et al. 2019, ValenciaMotoya $e t$ al. 2020) and cichlid fish (Gante et al. 2016, Svardel et al. 2020). Tracts of the southern $O$. korogwe genome with extensive evidence for hybridization (e.g. LG7, LG9 and LG17), may have resulted from introgressed alleles in those regions being favoured by selection. In North America hybridization between introduced rainbow trout (Oncorhynchus mykiss) and native westslope cutthroat trout (Oncorhynchus clarkii lewisi), has led to multiple genomic variants being shared between the species, with selection repeatedly favouring some introduced alleles within the native species (Bay et al. 2019). Adaptive introgression has similarly been suggested to have led to multiple beneficial traits arising from close-relatives in many species groups, including Darwin's finches (Lamichhaney et al. 2015), snowshoe hares (Jones et al. 2018) and multiple plant taxa (Suarez-Gonzalez et al. 2018).

In comparisons of $O$. korogwe from Lake Nambawala and $O$. niloticus, regions of the genome with low levels of introgression (e.g. LG6, LG16 and LG19). This may be due to the presence of "barrier" loci that reduce gene flow and maintain species boundaries (Elmer et al. 2019). It is been shown that hybridization can suppress recombination rates in some genomic regions of hybrid trout (Ostberg et al. 2013). It has also been proposed that recombination is particularly strongly suppressed near genes associated with reproductive isolation among parent species, due to hybrids have a low relative fitness (Hvala et al. 2018). In particularly, hybridization could lead to the breakup of coadapted "supergene" clusters, leading to low fitness hybrids, and so these large genomic regions would in principle be among most resistant to introgression. Positive associations between recombination rate of genome and admixture have been described in humans and swordtail fishes (Schumer et al. 2018), as well as sympatric pairs of Heliconius butterflies (Martin et al. 2019). However, accurate estimations of 
recombination rate require genotype data from more extensive population sampling than has been undertaken for our study, so this remains an untested yet plausible explanation for at some of the heterogeneity observed.

\section{Conservation implications}

Our results support the concept that the northern and southern $O$. korogwe populations are long-diverged and phenotypically-divergent evolutionarily significant units. These may require consideration as discrete species, which will have implications for the biodiversity of tilapias of East Africa. However, the results also illustrate that genetic structure within the newly discovered populations of $O$. korogwe has already been impacted by the invasive species $O$. niloticus. Similarly, the results also show $O$. niloticus has hybridized with $O$. placidus in the neighbouring Ruvuma drainage. Species introductions can have non-reversible impacts on genetic diversity (Dudgeon et al. 2006), and therefore the presence of this highly invasive species in these lakes is of considerable concern for the long-term conservation status for these populations. Hybridization could have larger impacts on the genetic diversity of this population over time, especially given evidence from other lakes where $O$. niloticus have been introduced (e.g. Deines et al. 2014) and given the lack of understanding of the long-term fitness consequences of these interaction. Although there is some evidence that hybridization could introduce advantageous alleles into the population, our findings suggest that these southern $O$. korogwe populations are likely to be locally adapted to the southern lakes. Therefore, introgression may have negative outcomes for the genetic uniqueness of the $O$. korogwe populations at least.

Our results clearly demonstrate an ongoing threat to unique southern $O$. korogwe populations, and longterm monitoring of the genetic and phenotypic diversity within the studied lakes will yield insights into changes of their status. We suggest that clear conservation actions could be implemented. Given the removal of $O$. niloticus from the southern lakes would be impractical, conservation of the unique genetic resources within the southern lakes would be best done through the identification of potential ark sites. For this research we sampled three of the water bodies in close proximity to the towns of Lindi and Rutamba, and it is possible that $O$. korogwe populations unaffected by $O$. niloticus are present in four additional proximate water bodies that we have not yet been surveyed. Each of these potential ark lakes will need to be intensively investigated to determine the species of fish present, and the potential for $O$. niloticus colonisation via natural waterways. In the absence of the suitable ark sites, the ex-situ conservation could be implemented. In both conservation strategies, genome-wide sequencing would be useful to confirm the genetic purity of the stocks, as this study has shown a clear signal of introgression in individuals of $O$. korogwe from Lake Nambawala that were assumed to purebred on the basis of the phenotypes. Therefore, this study underlines the value of using genome-wide sequencing for assessing the conservation status of taxa under threat from hybridization with introduced species.

\section{Acknowledgements}

The work was funded by Royal Society-Leverhulme Trust Africa Awards AA100023 and AA130107 to MJG, BPN and GFT, BBSRC award BB/M026736/1 to GFT, MJG and FdP, and and BBSRC award $\mathrm{BB} / \mathrm{P} 016774 / 1$ to WH and FdP We thank the Tanzania Commission for Research and Technology (COSTECH) for fieldwork approval and permits, and staff of the Tanzania Fisheries Research Institute for contributions to fieldwork. We thank Nasser Kazosi for help with sample collection in Uganda, made under permit number IMP/GEN/2014/06. This research was supported in part by the NBI Computing infrastructure for Science (CiS) group through use of the CiS high-performance computing cluster for the analysis of the whole genome resequence data.

\section{Author Contributions}

GFT, MJG and FDP conceived the study. MJG, GFT and BPN designed fieldwork and sampling. TB, SJB, AGPF, CAGJ, BPN, AS, GFT, RT and MJG conducted or supervised fieldwork, or collected data. TB, AGPF, AGC, MJG, GE and WH designed and performed the analysis. TB, AGPF and MJG wrote the first draft of the manuscript. All authors commented on and edited the final manuscript. 


\section{Data Accessibility Statement}

- Microsatellite genotype data - DOI: 10.5523/bris.2ka0x87ea99pk221rw3dahmzbn

- Morphological data - DOI: 10.5523/bris.2ka0x87ea99pk221rw3dahmzbn

- DNA resequencing data (raw reads) - to be deposited at the European Nucleotide Archive; Project number: PRJEB36772 on acceptance

- DNA resequencing data (vcf files) - to be deposited at the University of Bristol RDSF on acceptance.

\section{References}

Alexander, D. H., Novembre, J., \& Lange, K. (2009). Fast model-based estimation of ancestry in unrelated individuals. Genome Research, 19, 1655-1664.

Almodóvar, A., Nicola, G.G., Leal, S., Torralva, M. and Elvira, B. (2012). Natural hybridization with invasive bleak Alburnus alburnus threatens the survival of Iberian endemic calandino Squalius alburnoides complex and Southern Iberian chub Squalius pyrenaicus. Biological Invasions, 14, 2237-2242.

Andrews, S. (2010). FastQC: a quality control tool for high throughput sequence data. Retrieved from http://www.bioinformatics.babraham.ac.uk/projects/fastqc

Angienda, P.O., Lee, H.J., Elmer, K.R., Abila, R., Waindi, E.N., \& Meyer, A. (2011). Genetic structure and gene flow in an endangered native fish (Oreochromis esculentus) compared to invasive Nile Tilapia (Oreochromis niloticus) in Yala swamp, East Africa. Conservation Genetics, 12, 243-255.

Arroita, M., Flores, L., Larrañaga, A., Martínez, A., Martínez-Santos, M., Pereda, O., Ruiz-Romera, E., Solagaistua, L., \& Elosegi, A. (2017). Water abstraction impacts stream ecosystem functioning via a wetted-channel contraction. Freshwater Biology, 62, 243-257.

Barel, C.D.N., van Oijen, M.J.P., Witte, F., \& Witte-Maas, E.L.M. (1977). An introduction to the taxonomy and morphology of the Haplochromine Cichlidae from Lake Victoria. Netherlands Journal of Zoology, 27, 381389.

Bay, R.A., Taylor, E.B. \& Schluter, D. (2019). Parallel introgression and selection on introduced alleles in a native species. Molecular Ecology, 28, 2802-2813.

Belkhir K., Borsa P., Chikhi L., Raufaste N. \& Bonhomme F. (1999). GENETIX 4.05, logiciel sous Windows TM pour la génétique des populations. Laboratoire Génome, Populations, Interactions, CNRS UMR 5171, Université de Montpellier II, Montpellier (France).

Boecklen, W.J. \& Howard, D.J. (1997). Genetic analysis of hybrid zones: numbers of markers and power of resolution. Ecology, 78, 2611-2616.

Bradbeer, S.J., Harrington, J., Watson, H., Warraich, A., Shechonge, A., Smith, A. ...Genner, M.J. (2019). Limited hybridization between introduced and critically endangered indigenous tilapia fishes in northern Tanzania. Hydrobiologia, 832, 257-268.

Brawand, D., Wagner, C., Li, Y.,, Malinsky, M., Keller, I., Fan, S. .. Di Palma, F. (2014). The genomic substrate for adaptive radiation in African cichlid fish. Nature, 513, 375-381.

Browning, S. R. \& Browning, B. L. (2007). Rapid and accurate haplotype phasing and missing-data inference for whole-genome association studies by use of localized haplotype clustering. American Journal of Human Genetics, 81, 1084-1097.

Brummett, R.E., \& Williams, M.J. (2000). The evolution of aquaculture in African rural and economic development. Ecological Economics, 33, 193-203.

Canonico, G.C., Arthington, A., McCrary, J.K. \& Thieme, M.L. (2005). The effects of introduced tilapias on native biodiversity. Aquatic Conservation: Marine and Freshwater Ecosystems, 15, 463-483.

Colombo, M., Indermaur, A., Meyer, B.S., \& Salzburger, W. (2016). Habitat use and its implication to functional morphology: niche partitioning and the evolution of locomotory morphology in Lake Tanganyikan cichlids (Perciformes: Cichlidae). Biological Journal of the Linnean Society, 117, 536-550.

Conte, M.A., Joshi, R., Moore, E.C., Nandamuri, S.P., Gammerdinger, W.J., Roberts, R.B., Carleton, K.L., Lien, S. \& Kocher, T.D. (2019). Chromosome-scale assemblies reveal the structural evolution of African cichlid genomes. Gigascience, 8, giz030.

Conte, M.A., Clark, F.B., Roberts, R.B., Xu, L., Tao, W., Zhou, Q., Wang, D. and Kocher, T.D. (2020). Evolution of a sex megachromosome. bioRxiv. https://doi.org/10.1101/2020.07.02.182808

D'Amato, M.E., Esterhuyse, M.M., Van Der Waal, B.C., Brink, D. \& Volckaert, F.A. (2007). Hybridization and phylogeography of the Mozambique tilapia Oreochromis mossambicus in southern Africa evidenced by mitochondrial and microsatellite DNA genotyping. Conservation Genetics, 8, 475-488. 
bioRxiv preprint doi: https://doi.org/10.1101/2020.08.06.240002; this version posted August 7, 2020. The copyright holder for this preprint (which was not certified by peer review) is the author/funder, who has granted bioRxiv a license to display the preprint in perpetuity. It is made available under aCC-BY 4.0 International license.

Deines, A.M., Bbole, I., Katongo, C., Feder, J.L. \& Lodge, D.M. (2014). Hybridization between native Oreochromis species and introduced Nile tilapia O. niloticus in the Kafue River, Zambia. African Journal of Aquatic Science, 39, 23-34.

Deines, A.M., Bunnell, D.B., Rogers, M.W., Bennion, D., Woelmer, W., Sayers, M.J., ... Beard Jr., T.D. (2017). The contribution of lakes to global inland fisheries harvest. Frontiers in Ecology and the Environment, 15, 293-298.

Dudgeon, D., Arthington, A.H., Gessner, M.O., Kawabata, Z., Knowler, D.J., Leveque, C., ... Sullican, C.A. (2006). Freshwater biodiversity: importance, threats, status and conservation challenges. Biological Reviews, 81, 163-182.

Eknath, A.E. and Hulata, G., 2009. Use and exchange of genetic resources of Nile tilapia (Oreochromis niloticus). Reviews in Aquaculture, 1, 197-213.

Elmer, K.R., 2017. Barrier loci and progress towards evolutionary generalities. Journal of Evolutionary Biology, 30, 1491-1493.

Evanno, G., Regnaut, S., \& Goudet, J. (2005). Detecting the number of clusters of individuals using the software STRUCTURE: a simulation study. Molecular Ecology, 14, 2611-2620.

Excoffier, L. \& Lischer, H.E.L. (2010). Arlequin suite version 3.5: A new series of programs to perform population genetics analyses under Linux and Windows. Molecular Ecology Resources, 10, 564-567.

Fessehaye, Y., El-bialy, Z., Rezk, M.A., Crooijmans, R., Bovenhuis, H. \& Komen, H. (2006). Mating systems and male reproductive success in Nile tilapia (Oreochromis niloticus) in breeding hapas: a microsatellite analysis. Aquaculture, 256, 148-158.

Firmat, C., Alibert, P., Losseau, M., Baroiller, J.F. \& Schliewen, U.K. (2013). Successive invasion-mediated interspecific hybridizations and population structure in the endangered cichlid Oreochromis mossambicus. PLOS ONE, 8, e63880.

Fraser, D.J. \& Bernatchez, L. (2001). Adaptive evolutionary conservation: towards a unified concept for defining conservation units. Molecular Ecology, 10, 2741-2752.

Ford, A.G.P., Bullen, T.R., Pang, L., Genner, M.J., Bills, R., Flouri, T., .. Day, J.J. (2019). Molecular phylogeny of Oreochromis (Cichlidae: Oreochromini) reveals mito-nuclear discordance and multiple colonisation of adverse aquatic environments. Molecular Phylogenetics and Evolution. 136, 215-226.

Gainsford, A. (2014). Hierarchical behavior, habitat use, and species size differences shape evolutionary outcomes of hybridization in a coral reef fish. Journal of Evolutionary Biology, 28, 205-222.

Gante, H.F., Matschiner, M., Malmstrøm, M., Jakobsen, K.S., Jentoft, S. \& Salzburger, W., (2016). Genomics of speciation and introgression in Princess cichlid fishes from Lake Tanganyika. Molecular Ecology, 25, 6143-6161.

Genner, M.J., Ngatunga, B.P. Turner (2018) A Guide to the Tilapia fishes of Tanzania. Available at: http://bit.ly/TZTilapiaGuide. Accessed 27 July 2020.

Hahn, C., Genner, M.J., Turner, G.F. \& Joyce, D.A. (2017). The genomic basis of adaptation to the deep water 'twilight zone' in Lake Malawi cichlid fishes. Evolution Letters, 1-4, 184-198.

Hahn, M.W. \& Hibbins, M.S. (2019). A three-sample test for introgression. Molecular Biology and Evolution, 36, 2878-2882.

Hata, H., Uemura, Y., Ouchi, K. and Matsuba, H., 2019. Hybridization between an endangered freshwater fish and an introduced congeneric species and consequent genetic introgression. PloS ONE, 14, e0212452.

Hayden, B., Pulcini, D., Kelly-Quinn, M., O’Grady, M., Caffrey, J., McGrath, A., \& Mariani, S. (2010). Hybridization between two cyprinid fishes in a novel habitat: genetics, morphology and life-history traits. BMC Evolutionary Biology, 10, 1-11.

Horreo, J.L., Ayllon, F., Perez, J., Beall, E., and Garcia-Vazquez, E. (2011). Interspecific hybridization, a matter of pioneering? Insights from Atlantic salmon and Brown trout. Journal of Heredity, 102, 237-242.

Hvala, J.A., Frayer, M.E. and Payseur, B.A. (2018). Signatures of hybridization and speciation in genomic patterns of ancestry. Evolution, 72, 1540-1552.

Jombart, T., \& Ahmed, I. (2011). Adegenet 1.3-1: new tools for the analysis of genome-wide SNP Data. Bioinformatics, 21, 3070-1.

Jones, M.R., Mills, L.S., Alves, P.C., Callahan, C.M., Alves, J.M., Lafferty, D.J., ... Good, J.M. (2018). Adaptive introgression underlies polymorphic seasonal camouflage in snowshoe hares. Science, 360, 1355-1358.

Josupeit, H. (2010). World supply and demand of tilapia 2010. Paper presented at the Third International Technical and Trade Conference and Exposition on Tilapia, 27-29 October 2010. Kuala Lumpur: Malaysia.

Kalacska, M., Arroyo-Mora, J.P., Lucanus, O., \& Kishe-Machumu, M.A. (2017). Land cover, land use, and climate change impacts on endemic cichlid habitats in northern Tanzania. Remote Sensing, 9, 623.

Katoh, K. \& Standley, D.M. (2013). MAFFT multiple sequence alignment software version 7: improvements in performance and usability. Molecular Biology and Evolution, 30, 772-780.

Klingenberg, C.P. (2011). MorphoJ: an integrated software package for geometric morphometrics. Molecular Ecology Resources, 11, 353-357. 
Kopelman, N.M., Mayzel, J., Jakobsson, M., Rosenberg, N.A. \& Mayrose, I. (2015). Clumpak: a program for identifying clustering modes and packaging population structure inferences across K. Molecular Ecology Resources, 15, 1179-1191.

Lamichhaney, S., Berglund, J., Almén, M.S., Maqbool, K., Grabherr, M., Martinez-Barrio, A., ... Grant, B.R. (2015). Evolution of Darwin's finches and their beaks revealed by genome sequencing. Nature, 518, 371375.

Lévêque, C., 1995. Role and consequences of fish diversity in the functioning of African freshwater ecosystems: a review. Aquatic Living Resources, 8, 59-78.

Lind, C.E., Brummett, R.E. \& Ponzoni, R.W. (2012). Exploitation and conservation of fish genetic resources in Africa: issues and priorities for aquaculture development and research. Reviews in Aquaculture, 4, 125141.

Li, H. (2013). Aligning sequence reads, clone sequences and assembly contigs with BWA-MEM. ArXiv Preprint. doi:arXiv:1303.3997.

Li, H., Handsaker, B., Wysoker, A., Fennell, T., Ruan, J., Homer, N., ... Durbin, R. (2009). The Sequence Alignment/Map format and SAMtools. Bioinformatics, 25, 2078-2079.

Liu, F., Sun, F., Li, J., Xia, J.H., Lin, G., Tu, R.J., \& Yue, G.H. (2013). A microsatellite-based linkage map of salt tolerant tilapia (Oreochromis mossambicus x Oreochromis spp.) and mapping of sex-determining loci. BMC Genomics, 14, 1-14.

Lowe, R.H. (1955). New species of Tilapia (Cichlidæ) from Lake Jipe and the Pangani River, East Africa, with notes on the biology of these and Lake Victoria species grown in ponds. Bulletin of the British Museum of Natural History, 2, 350-368.

Lowe-McConnell, R.H. (1982). Tilapias in fish communities. In: The biology and culture of tilapia. Eds: Pullin, R.S.V. and Lowe-McConnell, R.H. International Centre for Living Aquatic Resources Management, Manila.

Malinsky M., Svardal H., Tyers A.M., Miska E.A., Genner M.J., Turner G.F., \& Durbin R. (2018). Whole-genome sequences of Malawi cichlids reveal multiple radiations interconnected by gene flow. Nature Ecology and Evolution, 2, 1940-1955.

Mandeville, E.G., Walters, A.W., Nordberg, B.J., Higgins, K.H., Burckhardt, J.C. \& Wagner, C.E. (2019). Variable hybridization outcomes in trout are predicted by historical fish stocking and environmental context. Molecular Ecology, 28, 3738-3755.

Martin, S.H., \& Jiggins, C.D. (2017). Interpreting the genomic landscape of introgression. Current Opinion in Genetics \& Development, 47, 69-74.

Martin, S.H. \& Van Belleghem, S.M. (2017). Exploring evolutionary relationships across the genome using topology weighting. Genetics, 206, 429-438.

Martin, S.H., Davey, J.W., Salazar, C., \& Jiggins, C.D. (2019). Recombination rate variation shapes barriers to introgression across butterfly genomes. PLoS Biology, 17, e2006288.

Martinuzzi, S., Januchowski-Hartley, S.R., Pracheil, B., McIntyre, P.B., Plantinga, A.J., Lewis, D.J., \& Radeloff, V.C. (2014). Threats and opportunities for freshwater conservation under future land use change scenarios in the United States. Global Change Biology, 20, 113-124.

McKenna, A., Hanna, M., Banks, E., Sivachenko, A., Cibulskis, K., Kernytsky, A., ... DePristo, M.A. (2010). The Genome Analysis Toolkit: A MapReduce framework for analyzing next-generation DNA sequencing data. Genome Research, 20, 1297-1303.

Millennium Ecosystem Assessment (2016). Ecosystems and human well-being: Synthesis. Washington, DC: Island Press.

Muhlfeld, C.C., Kovach, R.P., Jones, L.A., Al-Chokhachy, R., Boyer, M.C., Leary, R.F., Lowe, W.H., Luikart, G. \& Allendorf, F.W. (2014). Invasive hybridization in a threatened species is accelerated by climate change. Nature Climate Change, 4, 620-624.

Nelson, C.M. (1995). Male size, spawning pit size and female mate choice in a lekking cichlid fish. Animal Behaviour 50, 1587-1599.

Nguyen, L.T., Schmidt, H.A., von Haeseler, A., \& Minh, B.Q. (2015). IQ-TREE: a fast and effective stochastic algorithm for estimating maximum-likelihood phylogenies. Molecular Biology and Evolution, 32, 268-274.

Ogutu-Ohwayo, R. (1990). The decline of the native fishes of lakes Victoria and Kyoga (East Africa) and the impact of introduced species, especially the Nile perch, Lates niloticus, and the Nile tilapia, Oreochromis niloticus. Environmental Biology of Fishes, 27, 81-96.

Ostberg, C.O., Hauser, L., Pritchard, V.L., Garza, J.C. and Naish, K.A. (2013). Chromosome rearrangements, recombination suppression, and limited segregation distortion in hybrids between Yellowstone cutthroat trout (Oncorhynchus clarkii bouvieri) and rainbow trout (O. mykiss). BMC Genomics, 14, 570.

Parsons, K.J., Son, Y.H., \& Albertson, R.C. (2011). Hybridization promotes evolvability in African cichlids: Connections between transgressive segregation and phenotypic integration. Evolutionary Biology, 38, 306315. 
Pritchard, J.K., Stephens, M., \& Donnelly, P. (2000). Inference of population structure using multilocus genotype data. Genetics, 155, 945-959.

Purcell, S., Neale, B., Todd-Brown, K., Thomas, L., Ferreira, M.A., Bender, D., ... Sham, P.C. (2007). PLINK: a toolset for whole genome association and population-based linkage analysis. American Journal of Human Genetics, 81, 559-575.

Quinlan, A.R. \& Hall, I.M. (2010). BEDTools: a flexible suite of utilities for comparing genomic features. Bioinformatics, 26, 841-842.

Rognon, X., \& Guyomard, R. (2003). Large extent of mitochondrial DNA transfer from Oreochromis aureus to O. niloticus in West Africa. Molecular Ecology, 12, 435-445.

Rohlf, F.J. (2004). TpsDig Version 1.4. Department of Ecology and Evolution. State University of New York at Stony Brook, New York.

Rousset F. (2008). Genepop'007: a complete re-implementation of the genepop software for Windows and Linux. Molecular Ecology Resources, 8, 103-106.

Saju, J.M., Lee, W-J., \& Orban, L. (2010). Characterization of nine novel microsatellites isolated from Mozambique tilapia, Oreochromis mossambicus. Conservation Genetics Resources, 2, 287-385.

Sala, O.E., Chapin, F.S., Armesto, J.J., Berlow, R., Bloomfield, J., Dirzo, R., ... Wall, D.H. (2000). Global biodiversity scenarios for the year 2100. Science, 287, 1770-1774.

Schneider, R.F., \& Meyer, A. (2017). How plasticity, genetic assimilation and cryptic genetic variation may contribute to adaptive radiations. Molecular Ecology, 26, 330-350.

Schumer, M., Xu, C., Powell, D.L., Durvasula, A., Skov, L., Holland, C., ... Przeworski, M. (2018). Natural selection interacts with recombination to shape the evolution of hybrid genomes. Science, 360, 656-660.

Seehausen, O., Butlin, R.K., Keller, I., Wagner, C.E., Boughman, J.W., Hohenlohe, P.A., Peichel, C.L., Saetre, G.P., Bank, C., Brännström, А. \& Brelsford, A. (2014). Genomics and the origin of species. Nature Reviews Genetics, 15, 176-192.

Shechonge, A., Ngatunga, B.P., Tamatamah, R., Bradbeer, S.J., Harrington, J., Ford, A.G. ... Genner, M.J. (2018). Losing cichlid fish biodiversity: genetic and morphological homogenization of tilapia following colonization by introduced species. Conservation Genetics, 19, 1199-1209.

Shechonge, A., Ngatunga, B.P., Bradbeer, S.J., Day, J.J., Freer, J.J., Ford, A.G.P., ... Genner, M.J. (2019). Widespread colonization of Tanzanian catchments by introduced Oreochromis tilapia fishes: the legacy from decades of deliberate introduction. Hydryobiologia, 832, 235-253.

Skelton, P.H., (2001). A complete guide to the freshwater fishes of southern Africa. Capte Town: Struik.

Snoeks, J., Hanssens, M., Ngatunga, B., Chisambo, J., \& Nyasulu, T. (2004). Identification, distribution and taxonomy of Malawian cichlids: a look to the future. In: M.J. Snoeks, ed. 2004. The cichlid diversity of Lake Malawi/Nyasa.Niassa: identification, distribution and taxonomy. 354-356.

Stacklies, W., Redestig, H., Scholz, M., Walther, D., \& Selbig, J. (2007) pcaMethods - a Bioconductor package providing PCA methods for incomplete data. Bioinformatics, 223, 1164-1167.

Svardal, H., Quah, F.X., Malinsky, M., Ngatunga, B.P., Miska, E.A., Salzburger, W., Genner, M.J., Turner, G.F. \& Durbin, R. (2020). Ancestral hybridization facilitated species diversification in the Lake Malawi cichlid fish adaptive radiation. Molecular Biology and Evolution, 37, 1100-1113.

Stamatakis, A. (2014) RAxML version 8: a tool for phylogenetic analysis and post-analysis of large phylogenies. Bioinformatics, 30, 1312-1313.

Suarez-Gonzalez, A., Lexer, C., \& Cronk, Q.C. (2018). Adaptive introgression: a plant perspective. Biology Letters, 14, 20170688.

Trewavas, E. (1983). Tilapiine fishes of the genera Sarotherodon, Oreochromis and Danakilia. London, UK: British Museum (Natural History).

Valencia-Montoya, W.A., Elfekih, S., North, H.L., Meier, J.I., Warren, I.A., Tay, W.T., Gordon, K.H., Specht, A., Paula-Moraes, S.V., Rane, R. \& Walsh, T.K. (2020). Adaptive introgression across semipermeable species boundaries between local Helicoverpa zea and invasive Helicoverpa armigera moths. Molecular Biology and Evolution, msaa108, https://doi.org/10.1093/molbev/msaa108.

Wang, J., Street, N.R., Park, E.J., Liu, J. \& Ingvarsson, P.K. (2020). Evidence for widespread selection in shaping the genomic landscape during speciation of Populus. Molecular Ecology, 29, 1120-1136. 